\title{
Feeling of women regarding the use of the Billings Ovulation Method
}

\author{
Sentimento de mulheres em relação ao uso do Método de Ovulação Billings
}

Eliane Vieira dos Santos ${ }^{1}$, Rita de Cássia Maria dos Santos Frazão ${ }^{1}$, Sheyla Costa de Oliveira ${ }^{1}$

Objective: to know the feelings of women regarding the use of the Billings Ovulation Method as family planning. Methods: a qualitative study was carried out with eight women through a semi-structured interview and data were analyzed through the thematic analysis. Results: the results were organized into four main thematic categories: Use of the method and self-knowledge of the body; Insecurity as to the use of the method; Choice based on religious principles; and Complicity of the couple in the execution of the method. Conclusion: participants using the Billings Ovulation Method were satisfied and safe, and the participation of the partner was critical to the use of the method as natural family planning.

Descriptors: Natural Family Planning Methods; Ovulation; Sexual Behavior.

Objetivo: conhecer os sentimentos de mulheres em relação ao uso do Método de Ovulação Billings como planejamento familiar. Métodos: estudo qualitativo, realizado com oito mulheres, por meio de entrevista semiestruturada e dados analisados por meio da análise temática. Resultados: organizados em quatro categorias temáticas principais: Uso do método e autoconhecimento do corpo; Insegurança quanto ao uso do método; Escolha baseada em princípios religiosos; e Cumplicidade do casal na execução do método. Conclusão: as mulheres participantes que utilizavam o Método de Ovulação Billings sentiam-se satisfeitas e seguras, sendo a participação do parceiro fundamental para ocorrência do método como planejamento familiar natural.

Descritores: Métodos Naturais de Planejamento Familiar; Ovulação; Comportamento Sexual.

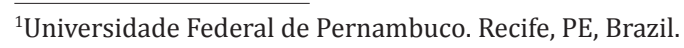

Corresponding author: Sheyla Costa de Oliveira

Avenida Prof. Morais Rêgo, 123-Cidade universitária, CEP: 50670-90. Recife, PE, Brazil. E-mail:costa.shy@gmail.com 


\section{Introduction}

Family planning is the right of every citizen and is defined as the set of actions of fertility regulation that guarantees equal rights of constitution, limitation or increase of the offspring by the woman, by the man or by the couple ${ }^{(1)}$.

The Brazilian Ministry of Health, based on the provisions of the Family Planning Law (Law No. 9.263/96), determines as a responsibility of health professionals to assist in conception and contraception, striving to inform individuals about the options and objectives of the methods available. These professionals, among them the nurse, must engage in providing accurate information to the users, so that they can participate freely and actively of their choices ${ }^{(1-2)}$.

There are varieties of contraceptive methods, which allow couples to choose according to their needs, among them: natural methods (cervical mucus method, ovulation or Billings method, calendar-based method and basal temperature method); hormonal methods (pills, patches, injections, skin implants, vaginal ring, emergency contraception, popularly known as morning-after pill); barrier methods (female condom, male condom, diaphragm and spermicide); intrauterine device with copper or with hormones); and definitive methods (vasectomy and tubal ligation $)^{(3)}$.

For natural methods, we have the Natural Family Planning, when the regulation of fertility is performed through the observation of signs and symptoms that occur naturally in the fertile and infertile phases of the menstrual cycle, with restriction of sexual relations during the fertile phase, in the cases in which the couple wants to avoid pregnancy. Thus, the Billings Ovulation Method is based on the identification of the fertile period of the menstrual cycle through self-observation of cervical mucus characteristics, indicating the fertile period ${ }^{(4)}$.

For 27 years, medical researchers in Melbourne, Australia, have studied fertile and infertile cycles based on the cervical mucus characteristics, and concluded that the sensation produced by the mucus, as well as its appearance, helped women to recognize the onset of fertility and control the conception. Also, in the 1970s, from the studies of John Billings, the rules of the Billings Ovulation Method were officially created, with a proven efficacy of $97.0 \%$, being scientifically accepted by the World Health Organization as an effective contraceptive method ${ }^{(5)}$.

However, the issues that apply to reproductive and family planning still pose challenges, since there is a considerable distance between what is advocated in the actions of promotion and attention to sexual and reproductive health and what is actually experienced by Brazilian women of childbearing age ${ }^{(6)}$.

Inadequate knowledge about any contraceptive method can be a factor of resistance to acceptability and use of the method. Likewise, the high level of knowledge about contraceptive methods will not determine behavior change if they are not accessible to the free choice of the population ${ }^{(7)}$.

Therefore, given the difficulties presented in relation to contraceptive methods and family planning, the relevance of the study is acknowledged through the possibility of increasing the knowledge about what users of natural methods of family planning feel, having as a research question: what is the women's feeling regarding the use of the Billings Ovulation Method as natural family planning?

In this sense, this study aimed to know the feelings of women regarding the use of the Billings Ovulation Method.

\section{Methods}

This is a qualitative study, which applies to the detailed study of a particular fact, object, group of people or social actor and phenomena of reality. This procedure seeks to obtain reliable information to explain in depth the meaning and characteristics of each context in which the research object is inserted ${ }^{(8)}$. 
The study participants were women who used the Billings Ovulation Method, married and of reproductive age (women aged 15-49 years) ${ }^{(9)}$. Adolescents and women with impaired cognitive understanding regarding the guiding question were excluded from the study, thus considered as an exclusion criteria.

The data saturation criterion was used to indicate the sample size of the subjects involved; such criterion is defined as the suspension of inclusion of new participants when the data start to present, in the researcher's evaluation, redundancy or repetition, not being considered relevant to persist in collecting data $^{(8)}$.

The study was conducted in the city of Recife, Brazil, in the Catholic communities of Maanaim and Shallom, which promote meetings and semi-annual training of couples at their headquarters, with a focus on the promotion of the reproductive health of its members, in which instructors of the Billings Ovulation Method, accredited by the National Confederation of Family Natural Planning (an organization linked to the World Organization of the Billings Ovulation Method) work as facilitators for couples who are invited to attend courses on natural family planning.

For the collection of data, a script of semi-structured interviews was elaborated by the authors of the study, containing the following guiding question: what is the feeling of women in relation to the use of the Billings Ovulation Method as Natural Family Planning? In addition, questions were asked to know the social profile of the interviewees.

The data collection was carried out using a smartphone voice recorder, in a private room or in places chosen by the participants, at the community headquarters, individually. Interview time varied according to each participant, on average 10 minutes.

To ensure anonymity, the interviewees were randomly identified with fictitious flower names: Rose (1), Daisy (2), Jasmine (3), Azalea (4), Dahlia (5), Violet (6), Hydrangea (7), Tulip (8).

For the analysis of data, the thematic analy- sis was used. There were three steps for the analysis process: pre-analysis - the data were ordered and the interviews were transcribed, preserving the speeches in full; analytical description - the material was transcribed and grouped into subcategories; processing of data and interpretations - subjected to a detailed and exhaustive analysis and then organized according to thematic categories ${ }^{(10)}$.

The study complied with the formal requirements contained in the national and international regulatory standards for research involving human beings.

\section{Results}

The participants were married, with a mean age of 34 years and mean time of eight years of use of the method. Seven women had never used another contraceptive method and all the interviewees had knowledge or instruction about the method discussed in this study.

After the thematic analysis, four categories emerged: Use of the Method and self-knowledge of the body; Insecurity as to the use of the Method; Choice based on religious principles; and Complicity of the couple in the execution of the Method.

\section{Use of the Method and self-knowledge of the body}

It was evidenced that the analyzed method provides self-perception of the bodily variations during the menstrual cycle and greater knowledge about the fertility. The interviewees reported how this knowledge allows identifying the fertile period and planning a pregnancy with safety. It is a method that gives us safety, because it is inscribed in the human body, inscribed in our nature ... of course it needs an observation, a deepening, a good perception, but it signals to me a safety path of fertility (Daisy). And the more I get to know the method, the more I get to know myself, the more I feel safe and see how important it is to experience this natural method for the woman and the couple (Azalea). Regarding the exact period that you 
are fertile, I think that it leaves no doubt ... for me it brings happiness, because it is a way for me to really perceive myself and to know myself (Hydrangea). I feel good about myself, doing this method, I feel healthier, it does not attack my body, every woman has a different method, because the cycle is unique, the cycle is different, the cycle is personal, that's it, so I need to know my body, to know my cycle, my temperament, my posture, my intimate posture, too, so knowing myself I feel safe, knowing exactly the day I ovulate (Rose). It is a method through which I can do my family planning in a natural way, through which I can prevent or plan a pregnancy...the best of this method is that I do not need to use any kind of drug or device that may bring harm to my health ... I have learned to observe my body, when I met the method, I began to know my body, I was able to identify my fertile period (Tulip).

\section{Insecurity as to the use of the Method}

It was observed that at the beginning of the use of the Method, there was uncertainty regarding the adequate use, including in some moments of the women's reproductive life, like in the postpartum period. But with the time of use and discipline, the couple reached confidence and started to do it well. Soon after I got married, at first, I was a bit insecure, I mean, I was used it when I was single, but when I got married it was different. But as I got to know myself, I realized that the Method really works for postponing a pregnancy or to get pregnant, and then I became more confident (Azalea). At first, the method was, I mean, I felt a bit insecure, but then, over time, I began to feel pretty safe ... when I had my first child, I was a bit insecure about the postpartum period, when we spend a time without ovulating, but today, I had a second child, then I already know, I already know myself more (Hydrangea).

\section{Choice based on religious principles}

It was evidenced a strong contribution of the religion and the ethical and moral principles of the couples in the choice of the Method, as well as the valorization of God as creator of the feminine fertility. I join myself to what the church recommends, I get closer to God, I get closer to my husband, I get closer to my family, I get closer to myself
(Rose). My feeling about the ovulation method is first of all gratitude to God for having the opportunity to have known the method, and I also feel that I am very grateful for my body, for being able to perceive myself, to perceive my fertility, to perceive how God creates with great perfection the feminine dimension for motherhood, for fertility (Daisy). It is worth valuing the body; it is worth using what is natural, what God has given us as a greater gift (Dahlia). So, by God's providence, the method came to my city; I got to know it and automatically stopped taking the pills, because I trusted the explanation they gave me, in all the training they gave me (Tulip).

\section{Complicity of the couple in the execution of the Method}

It was observed that the union of the couple in the execution of the Method is a motivating and determinant factor for its use. The interviewees reported the support of the spouse in the daily notes of perceived sensations, promoting dialogue, making the man co-responsible and protagonist in family planning. I need to know my cycle; the knowledge generated harmony between me and my husband, because there is no use in doing the method alone, the method is not only for the woman, it is for the couple. Coming to know this, then you follow this safe path of the method (Rose). Planning the family, planning the life itself, so for me it is a sure path of fertility also in the life of the couple, as married people, the experience of communion, dialogue; my husband participates a lot with me on this path, he helps me a lot, and this has made us grow a lot in unity and in marital harmony (Daisy). Because since it is my husband who takes notes, who does the notes, so it is also good for him because he is getting to know me and we are having this line as a couple, so for me it is very good because of that, and I indicate to anyone also; it is a natural, effective method that helps in the relationship (Azalea). And another thing about the partner is that I think it's a sense of respect, because he also has to help, and for me, it brings a lot of security about the relationship, I feel more respected regarding using this method (Hydrangea).

Regarding periodic continence (sexual abstinence during the fertile period), this study did not detect a problem or difficulty in using the Method, rather, this may bring on more freedom for the couple in 
order to show that the couple's marriage is not only based on sex, so, together, they can decide the most appropriate time to have sex, according to the interviewees. It increases the dialogue with my husband, because we have to talk when it is allowed and when it is not, and then we end up sharing our responsibility, because the responsibility has to come from both ... something that I thought about this method is that it, in relation to the conjugal act, I had such a thought, that it was very restricted, and with this method, I learned that on the contrary, it leaves people more free to have the conjugal act than 'limited', restricted, so we get even more free (Tulip).

\section{Discussion}

The study in question presents limitations due to the impossibility of generalizing the results, due to the specificity of the analyzed context, since the use of natural methods of family planning, especially the Billings Ovulation Method, by couples is not common, even among Catholic couples, being restricted to some groups. Moreover, the adopted study method, with a qualitative approach, allows us to refer only to a restricted, small, but depth universe.

A study conducted in the United States, with 58 Latin-American and black women, found an increase in the search for these women by natural methods, in which $17.0 \%$ of those were foreigners, $13.0 \%$ were from Latin American and 15.0\% were black women, however, as in Brazil, the instructions were still scarce and could reduce the effectiveness of the method, leading to a rate of $25.0 \%$ of failures, although the correct use reaches only 3 to $5.0 \%$ of failures ${ }^{(11)}$.

Women may be more likely to consider natural methods as family planning when health services present information in a positive manner, but the low utilization of these services may also be a result of the practitioners' lack of knowledge about these methods and their effectiveness, showing little preparation to guide the patients ${ }^{(12)}$. Thus, the results point to the need to strengthen the permanent education actions of these professionals.
The use of natural methods of family planning allows women to have a central role in reproductive planning, allowing greater knowledge of the anatomy and functioning of the organism, often allowing acceptance of their own body, facilitating the dialogue and participation of the partner ${ }^{(4)}$.

In this sense, the security regarding the use of these methods can be related to the information received, as well as to the time of use. Therefore, the participants reported that since the beginning of the use of the Billings Ovulation method, they have been monitored and guided in their community, and obtained the support of other women, feeling confidence as to the use as natural family planning.

It is essential that couples are monitored by trained professionals, since the use of any contraceptive method requires, in addition to the individual's determination, adequate information and periodic control $^{(12)}$.

Currently, family planning care in the country is predominantly offered by the Family Health Strategy teams, especially by the nurse, whose role is, among others, to provide guidelines, together with health education, to empower users through individual activities or in groups, in order to sensitize them to take responsibility for health care, providing a change in social behavior in relation to family planning ${ }^{(13)}$.

However, a study carried out with 50 users of the family planning service of a basic health unit aimed at verifying the knowledge, attitudes and practices of women living in a rural community regarding contraceptive methods identified that $20.0 \%$ of them controlled fertility without the assistance of a health professional, highlighting the gaps that still exist between theory and practice ${ }^{(14)}$.

Concerning the feeling of insecurity about the use of the Billings Ovulation Method, in addition to the difficulty of initial learning, as reported by some interviewees, this situation is partly explained by the fact that female fertility is strongly influenced by several factors, such as women's lifestyle, smoking, drug use, 
and environmental factors, such as illness or stress, all of which often cause hormonal changes in the menstrual cycle, making them confused, and preventing users from being able to clearly identify the mucus ${ }^{(12)}$. In postpartum period, for example, there is of course a change in the woman's fertility pattern, which makes observations more difficult, but does not contraindicate the use. In this period, it is important to use appropriate methods, considering the physiological and anatomical repercussions present at that time ${ }^{(15)}$.

Interviewees expressed the choice of the Billings Ovulation Method based on ethical and moral principles provided by religion. Such an outcome is interesting, since it is known that the Catholic Church is against the use of "artificial" contraceptive methods, according to which contraception, even for married people, should not be performed, and if necessary, couples should give space to or limit births, respecting the natural rhythms of the body, using the infertile periods of the female menstrual cycle for sexual intercourse. However, there is no statistically significant difference in the use of modern contraceptive methods between non-religious, Catholic or Evangelical women, that is, both artificial and natural methods are not chosen based on these principles, but rather on what is offered in the environment in which the woman is inserted and on the instructions they receive ${ }^{(16)}$.

In Brazil and in some other countries, despite the personal conceptions, principles and values, the lack of reliable information about natural methods motivates women to use other methods. Opposite to this, an exploratory and qualitative study carried out in the States of Enugu and Katsina, Nigeria, showed that when individuals are influenced by culture and religion, they tend to choose the method of family planning that is in accordance with the religion. Thus, when there is investment in the introduction of effective natural methods, this causes increase of contraceptive prevalence in countries with strong religious barriers to modern methods of family planning ${ }^{(17)}$.
The results of this study showed that male participation is determinant in the use of the method. Starting from the premise that conception is a natural result of the sexual act between man and woman, it is expected that contraception is also a phenomenon resulting from the combination of efforts between partners equally involved in this relationship ${ }^{(13)}$.

Motivating the participation of men in family planning is a challenge for the health service due to facts such as gender relations, services that are not available to the male category yet and the lack of recognition by health professionals about the need for attention and effective care for men ${ }^{(18)}$.

Although periodic continence (sexual abstinence in the fertile period) is seen as a disadvantage for the use of natural methods, it was not mentioned as such in this study. This result was similar to an observational, quantitative and analytical study that aimed to verify the knowledge, acceptability and use of natural family planning by users of contraceptive methods attended at a university hospital. In that study, 117 women were interviewed and there was no report of the abstinence period as a reason for not accepting the method ${ }^{(4)}$.

The international scientific literature points out that the sexual frequency of couples using natural methods in general is the same as those using other methods, with only a "shift" in the period in which sexual relations occur, to the infertile days of the female cycle, and becoming more frequent when the couple feels comfortable with the method ${ }^{(5)}$.

Given this, it is critical that health professionals provide effective assistance, providing health education with information on methods that include natural family planning, and assuring not only for women, but also for men, the possibility of having the central role in their own sexual and reproductive history with autonomy to plan or space the gestations according to the moment of the couple's life, since planning a gestation involves biopsychosocial issues of the individuals, so the couple needs to feel safe ${ }^{(4-5)}$. 


\section{Conclusion}

For the women participating in this study, the use of the Billings Ovulation Method is a means for self-knowledge of the body, which respects nature and is in accordance with religious principles, adding satisfaction and safety regarding fertility control, and motivating other women and/or couples regarding the use of the analyzed method.

Therefore, it was concluded that the female participants who used the Billings Ovulation Method were satisfied and safe, and the participation of the partner was fundamental for the execution of the method as a natural family planning.

\section{Collaborations}

Santos EV and Frazão RCMS contributed to the design, writing, analysis and interpretation of data. Oliveira SC contributed in the critical review of the intellectual content, writing and final approval of the version to be published.

\section{References}

1. Ministério da Saúde (BR). Decreto - Lei no 9.263, de 12 de Janeiro de 1996, ementa: regula o § 70 do art. 226 da Constituição Federal, que trata do planejamento familiar, estabelece penalidades e dá outras providências. Brasília: Ministério da Saúde; 1996.

2. Dombrowski JG, Pontes JA, Assis WALM. Atuação do enfermeiro na prescrição de contraceptivos hormonais na rede de atenção primária em saúde. Rev Bras Enferm. 2013; 66(6):827-32.

3. Costa A, Rosado L, Florêncio A, Xavier E. História do planejamento familiar e sua relação com os métodos contraceptivos. Rev Baiana Saúde Pública. 2013; 37(1):74-86.

4. Uchimura NS, Uchimura TT, Almeida LMM, Perego DM, Uchimura LYT. Conhecimento, aceitabilidade e uso do método Billings de planejamento familiar natural. Rev Gaúcha Enferm. 2011; 32(3):516-23.
5. Magalhães AC, Pereira DAS, Jardim DMB, Caillaux M, Sales VBL. Vivência da mulher na escolha do Método de Ovulação Billings. Rev Bras Enferm. 2013; 66(4):485-92.

6. Borges ALV, Cavalhieri FB, Hoga LAK, Fujimori E, Barbosa LR. Pregnancy planning: prevalence and associated aspects. Rev Esc Enferm USP. 2011; 45(2):1679-84.

7. Singh S, Darroch JE. Adding it up: costs and benefits of contraceptive services - Estimates for 2012 [Internet]. 2012 [cited 2016 Sept 13]. Available from:https://www.guttmacher.org/sites/default/files/report_pdf/aiu-2012-estimates_0.pdf

8. Oliveira MM. Como fazer pesquisa qualitativa. Recife: Editora Bagaço; 2005.

9. Ministério da Saúde (BR). Secretaria de Atenção à Saúde. Departamento de Atenção Básica. Saúde sexual e saúde reprodutiva. Brasília: Ministério da Saúde; 2010.

10. Bardin L. Análise de conteúdo. São Paulo: Edições 70; 2011.

11. Guzman L, Caal S, Peterson K, Ramos M, Hickman $\mathrm{S}$. The use of fertility awareness methods (FAM) among young adult Latina and black women: what do they know and how well do they use it? Use of FAM among Latina and black women in the United States?. J Contraception. 2013; 88(2):232-8.

12. Kelly PJ, Witt J, McEvers K, Enriquez M, Abshier P, Vasquez $\mathrm{M}$, et al. Clinician perceptions of providing natural family planning methods in title $\mathrm{x}$ funded clinics. J Midwifery Womens Health [Internet]. 2012 [cited Sept. 13];57(1):35-42. Available from: http://onlinelibrary.wiley.com/doi/10.1111/ j.1542-2011.2011.00107.x/t;jsessionid=EF18BF 94BD25B6A971DF662F31DF2F70.f02t01

13. Araújo KNC, Bastos LAC, Moura RFE, Silva RM. Planejamento familiar: significado para mulheres em idade reprodutiva. Ciênc Saúde Coletiva. 2011; 16(5):2415-24.

14. Nicolau AIO, Dantas RC, Gadelha APP, Pinheiro AKB. Conhecimento, atitude e prática de mulheres residentes no meio rural acerca dos métodos contraceptivos. Rev Eletr Enf [Internet]. 2012 [citado 2016 jul. 12]; 14(1):164-70. Disponível em: https://www.fen.ufg.br/fen_revista/v14/n1/ pdf/v14n1a19.pdf 
15. Mazzo MHSN, Brito RS, Santos FAPS. Atividades desenvolvidas pelo enfermeiro no pós-parto. Rev Enferm UERJ. 2014; 22(5):663-7.

16. Costa IGD, Carvalho AA. Uso de contracepção por mulheres de diferentes grupos religiosos: diferenças ou semelhanças? Rev Horizonte. 2014; 12(36):1114-39.
17. Ujuju C, Anyanti J, Adebayo SB, Muhammad F, Oluigbo 0 , Gofwan A. Religion, culture and male involvement in the use of the Standard Days Method: evidence from Enugu and Katsina states of Nigeria. Rev Int Nurs. 2011; 58(4):484-90.

18. Bezerra MS, Rodrigues DP. Representações sociais de homens sobre o planejamento familiar. Rev Rene. 2010; 11(4):127-34. 